\title{
Validation of a fast real-time PCR method to detect fraud and mislabeling in milk and dairy products
}

\author{
M. Di Domenico, ${ }^{1}$ M. Di Giuseppe, J. D. Wicochea Rodríguez, and C. Cammà \\ Ricerca e Sviluppo Biotecnologie, Istituto Zooprofilattico Sperimentale dell'Abruzzo e del Molise "G. Caporale", Via Campo Boario, \\ 64100 Teramo, Italy
}

\begin{abstract}
Fast real-time PCR TaqMan assays were developed and validated for species identification in dairy products. Based on the amplification of 12S rRNA and cytB partial genes of mitochondrial DNA, the methods were demonstrated to be sensitive, fast, and species-specific for Bos taurus, Ovis aries, Bubalus bubalis, and Capra hircus. The limit of detection calculated was lower than $1 \%$, and the efficiency was reported to be higher than $96 \%$ in every assay. An internal amplification control was used to detect possible false negatives. The method was validated by means of laboratory-prepared samples mixing different species. Moreover, 18 commercial dairy samples were analyzed by both real-time PCR and isoelectric focusing, the official European Union reference method. The 4 TaqMan assays were confirmed to be a useful tool for milk and dairy product authentication.
\end{abstract}

Key words: species identification, dairy products, isoelectric focusing, real-time PCR

\section{INTRODUCTION}

European Union food safety policy aims to protect customers not only from food pathogens but also from fraudulent species substitutions. Key priorities for these purposes are to ensure correct labeling of food and food traceability and to commission scientific studies if it is necessary to meet the requirements of European Commission Regulation No. 178/2002 (European Commission, 2002). Therefore, innovation in sensitive diagnostic tools is necessary for the authentication of processed food components. Milk and dairy products are an important part of the Mediterranean diet, which includes milk and processed dairy products of bovine, sheep, goat, and buffalo origin.

More than 100 European cheeses of great economic importance are classified as protected designation of origin (PDO) or protected geographical indications by

Received July 4, 2016.

Accepted September 23, 2016.

${ }^{1}$ Corresponding author: m.didomenico@izs.it
Regulation No. 1151/2012 of the European Commission (2012). A common problem in dairy products is the undeclared substitution of milk with dairy products of lower commercial value because differences in price and seasonal availability make this attractive for farmers and producers. Coupled with that, in terms of food technology, it is more difficult to develop some dairy products (e.g., Mozzarella cheese) from water buffalo milk because the stretching and mechanical spin become a challenge due to the rheological characteristics of buffalo milk casein compared with cow milk casein (Zhang et al., 2007). Unintentional mislabeling may also occur when several species are handled on the same manufacturing equipment. Whether fraudulent or unintentional, such mislabeled products give rise to economic loss and possible dangers to public health because milk proteins from any animals (most commonly bovine) are potential allergens (van Hengel, 2007).

The Commission Regulation (EC) No. 273/2008 of 5 March 2008 lays down detailed rules for the application of Council Regulation (EC) No. 1255/1999 (European Commission, 2008) regarding methods for the analysis and quality evaluation of milk and milk products. This regulation considers the legal limit of milk substitution to be $0.99 \%$, and alimentary fraud is defined when a value is equal or higher than $1 \%$. Moreover, the regulation defines isoelectric focusing (IEF) of $\gamma$-caseins as the official method for species identification.

Isoelectric focusing is a qualitative method that has proven to be sensitive and accurate for the detection of cow milk in mixed samples, but it shows several limitations: it is not a high-throughput method, it is not quantitative, and the analysis is time consuming. Moreover, the method cannot discriminate goat-sheep mixtures (Addeo et al., 1990; Mayer et al., 1997) and interpretation of the IEF profile can be equivocal (López-Calleja et al., 2007b). Furthermore, IEF is not applicable to products made of soy milk because some weak interfering bands have been observed. The same drawback was observed for the alternative protein-based method SDS-PAGE. Therefore, neither method is useful for the detection of cow milk in soy milk products (Mayer et al., 2012). 
Other methods have been used for species discrimination in dairy products based on the analysis of protein fraction, including ELISA (López-Calleja et al., 2007c), HPLC (Mayer, 2005), and matrix-assisted laser desorption/ionization time-of-flight mass spectrometry (Cozzolino et al., 2002). However, currently, DNA techniques are largely applied for species identification because they have proven to be reliable, specific, sensitive, and fast. In particular, real-time PCR does not require any postamplification step and can be easily automated, allowing the analysis of large numbers of samples (López-Calleja et al., 2007a,b; Cottenet et al., 2011; Dalmasso et al., 2011; Rentsch et al., 2013; Iwobi et al., 2015), and it permits quantitative or semiquantitative analysis.

The aim of the present study was to develop and validate 4 real-time PCR TaqMan assays based on the analysis of mitochondrial DNA (mtDNA) for species identification of Bos taurus, Bubalus bubalis, Ovis aries, and Capra hircus in milk and dairy products. These methods were validated by using laboratory-prepared samples. Moreover, 18 commercial milks and cheeses were analyzed comparing the real-time PCR results with those obtained by IEF, and 3 soy milk samples were analyzed by real-time PCR only.

\section{MATERIALS AND METHODS}

\section{Sample Preparation}

Bovine, buffalo, sheep, and goat milks, purchased directly from the farms, were used as reference materials. Binary mixtures were prepared by combining appropriate quantities by volume to obtain $1 \%$ of each single species in $99 \%$ of the other 3 species considered in this study. Then, DNA was isolated from $200 \mu \mathrm{L}$ of milk by using the Maxwell 16 Tissue DNA Purification kit (Promega, Madison, WI) according to the manufacturer's instructions. Moreover, 8 bovine whole milks, a PDO Parmigiano Reggiano bovine cheese, a Caciotta mista mixed fresh bovine/ovine cheese, a fresh cheese made with goat milk, a ripened goat cheese, a PDO Pecorino ovine cheese, and 5 buffalo fresh cheeses (3 PDO Mozzarella di Bufala Campana and 2 non-PDO Mozzarella di Bufala) were purchased from local retailers and analyzed by both real-time PCR and IEF. Three soy milk samples were also recovered from retailers and analyzed by real-time PCR.

The DNA was then extracted from $25 \mathrm{mg}$ of cheese or $200 \mu \mathrm{L}$ of milk as described above. Then, DNA was quantified by Quant-iT PicoGreen dsDNA Assay Kit (Invitrogen) following the provided protocol and diluted up to $1 \mathrm{ng} / \mu \mathrm{L}$.
Development of Real-Time PCR Assays. The mtDNA sequences from B. taurus (DQ186214), O. aries (DQ903212), B. bubalis (AF547270), and C. hircus (AJ885199) were aligned using the Lasergene (DNAStar) software. Mismatches on 12S rRNA gene sequences were selected to design species-specific primers and probes for buffalo (12S buffalo forward GTAACCTATGAAATGGGAAGAAATGG; 12S buffalo reverse TTACTGCTAAATCCTCCTTTGGTTATTAAT; 12S buffalo probe 6FAM-TACACCAAGAACACCCAAC-MGBNFQ) and goat (12S goat forward TAGGTCAAGGTGTAACCCATGGAA; 12S goat reverse ACTAAATCCTCCTTTGGTCATTAATTTCA; 12S goat probe 6FAM-CTTAAGAAAATTAATACGAAAGCC-MGBNFQ), whereas bovine and ovine sets were previously described (Cammà et al., 2012). In silico specificity was verified by Basic Local Alignment Search Tool analysis. Probes were labeled with the fluorescent reporter dye 6-carboxyfluorescein (FAM) on the $5^{\prime}$ end and with the minor groove bindernonfluorescent quencher (MGB-NFQ) on the $3^{\prime}$ end. The melting temperature, GC contents, and secondary structures (hairpin, self-dimers, and cross-dimers) of each primer and probe set were verified by the Primer Express 3.0 test tool (Applied Biosystems, Waltham, MA) and their concentrations were optimized.

Development of an Internal Amplification Control. The internal amplification controls (IAC) were developed for each assay as previously described (Cammà et al., 2012). The IAC was designed as a nontarget chimeric DNA fragment containing a portion of the acetyl-coenzyme A carboxylase gene (ACC) from turnip flanked by a portion of $c y t B$ or $12 S$ rRNA mtDNA sequence complementary to the primers. In each reaction tube, the IAC DNA was co-amplified with the target DNA using the same primers as for the test reaction. A cycle threshold $\left(\mathbf{C}_{\mathbf{t}}\right)$ value around 29 was produced by $0.1 \mathrm{fg}$ of the bovine and buffalo IAC DNA, $0.3 \mathrm{fg}$ of the ovine IAC DNA, and $0.1 \mathrm{fg}$ of the caprine IAC DNA.

Real-Time PCR Protocol. The real-time PCR was performed on the 7900HT Fast Real Time PCR System (Applied Biosystems) and analyzed by the software SDS 2.4 (Applied Biosystems). The primer and probe concentration, the DNA quantity for each reaction and the number of amplification cycles were carefully optimized as follows: the $20-\mu \mathrm{L}$ reaction mixtures contained $1 \times$ TaqMan Fast Universal PCR Master Mix, $300 \mathrm{n} M$ of specific MGB probe, $300 \mathrm{n} M$ of ACC probe, $900 \mathrm{n} M$ of specific oligonucleotide primers, nuclease-free water, $5 \mu \mathrm{L}$ of $1 \mathrm{ng} / \mu \mathrm{L}$ DNA, and $1 \mu \mathrm{L}$ of IAC DNA.

The reaction protocol used was $20 \mathrm{~s}$ at $95^{\circ} \mathrm{C}$ followed by 35 cycles of $1 \mathrm{~s}$ at $95^{\circ} \mathrm{C}$ and $20 \mathrm{~s}$ at $60^{\circ} \mathrm{C}$. 
Fluorescence readings were taken every cycle, and the logarithm of the increment in normalized fluorescence was plotted versus the numbers of cycles. The threshold level was fixed at the same middle exponential position for all runs. Triplicates of a no-template control and no-amplification control were used as negative controls for the analysis.

Validation: Sensitivity, Specificity, and Repeatability. The DNA was extracted from reference materials and 10-fold serial dilutions in nuclease-free water were prepared. Three replicates of 5 dilutions from $10 \mathrm{ng} / \mu \mathrm{L}$ to $1 \mathrm{pg} / \mu \mathrm{L}$ DNA were analyzed for the standard curve. Efficiency $(\mathrm{E})$ of the real-time PCR was calculated according to the formula $\mathrm{E}=\left(10^{-1 / \text { slope }}\right.$ - 1) × 100 (Vaerman et al., 2004).

Moreover, 24 replicates (in 3 different runs) for each of the five 2-fold DNA serial dilutions were analyzed to determine the limit of detection (LOD) by using Probit analysis (Finney, 1971) for bovine, ovine, buffalo, and goat data.

The repeatability of the methods was estimated calculating the coefficient of variation $(\mathrm{CV}=\mu / \sigma)$ relative to the analysis of 30 replicates in 3 different runs for both $100 \%$ and $1 \%$ reference DNA for each species-specific assay.

The specificity was determined using 4 replicates of DNA belonging to each nontarget species. Moreover, DNA extracted from human, horse, donkey, soy, almond, rice, and oat were tested by the 4 assays.

Isoelectric Focusing. Isoelectric focusing was performed following the protocol reported in annex XV of the Commission Regulation (European Commission) No. 1081/1996 using ready-to-use polyacrylamide gel plates and the PhastSystem Semi-automated Flatbed Electrophoresis System (GE Healthcare) as previously described (Cerquaglia and Avellini, 2004).

Evaluation was performed by comparing the protein patterns of the unknown sample with reference standards on the same gel. Detection of cow milk in cheeses from ewe, goat, and buffalo milk and mixtures of ewe, goat, and buffalo milk was done via the $\gamma 3$ - and $\gamma 2$-caseins, whose isoelectric points range between $\mathrm{pH}$ 6.5 and $\mathrm{pH} 7.5$. The peak area analysis of the $\gamma 2$ - and $\gamma 3$-caseins were carried on by the ImageScanner III, the LabScan v6.0, and the ImageQuant TL v7.0, all provided by GE Healthcare (Pittsburgh, PA).

\section{RESULTS}

\section{Efficiency, Specificity, and LOD of the Real-Time PCR}

Using DNA from reference materials, efficiency, specificity, and LOD of the real-time PCR assays were
Table 1. Real-time PCR assay: efficiency ${ }^{1}$

\begin{tabular}{lccc}
\hline Species & Slope & $\begin{array}{c}\text { Efficiency } \\
(\%)\end{array}$ & $\mathrm{R}^{2}$ \\
\hline Bovine & -3.40 & 97 & 0.99 \\
Buffalo & -3.42 & 96 & 0.99 \\
Sheep & -3.34 & 99 & 0.99 \\
Goat & -3.35 & 99 & 0.99 \\
\hline
\end{tabular}

${ }^{1}$ Efficiency (E) was calculated according to the formula $\mathrm{E}=\left(10^{-1 / \text { slope }}\right.$ $-1) \times 100$ (Vaerman et al., 2004).

calculated. The slope of the standard curve, the efficiency, and the coefficient of determination $\left(\mathrm{R}^{2}\right)$ for all 4 species are reported in Table 1.

The optimal DNA quantity to be loaded in the assay was established to be $5 \mathrm{ng}$, producing $\mathrm{C}_{\mathrm{t}}$ values between 22.9 and 23.7 for all species. For each assay, DNA from the other species were tested as nontarget DNA, using the same amount, and no cross-amplifications were observed. Similarly, no amplification was observed when analyzing human, horse, donkey, soy, almond, rice, and oat DNA. Moreover, the IAC showed the expected average $\mathrm{C}_{t}$ values of 30.1 for bovine, 29.9 for buffalo, 30.8 for sheep, and 30.5 for goat. The LOD for the different species were bovine, $0.5 \%$; buffalo, $<0.5 \%$; sheep, $0.05 \%$; and goat, $<0.05 \%$. More details are described in Table 2.

The method revealed a very high level of repeatability as assessed by the coefficient of variation. The coefficient of variation values were calculated for every assay as shown in Table 3 .

\section{Application of Real-Time PCR Assays in Labeled Commercial Samples}

The real-time PCR results confirmed the presence of the species indicated on the label in all of the 8 bovine milk samples and 4 cheeses produced with bovine, ovine, and goat milk. Moreover, the results of the Caciotta mista cheese showed a composition of both bovine milk and ovine milk as specified on the label.

Three of the 5 buffalo Mozzarella di Bufala [sample identification (ID) 14, 15, 18] fresh cheeses were shown to be composed of only buffalo milk as claimed, whereas

Table 2. Real-time PCR assay: limit of detection (LOD)

\begin{tabular}{lccc}
\hline Species & $\begin{array}{c}\text { LOD } \\
\left(\mathrm{cl}^{1} 95 \%\right)\end{array}$ & $\begin{array}{c}\text { Lower } \\
\mathrm{cl}^{1}\end{array}$ & $\begin{array}{c}\text { Upper } \\
\mathrm{cl}^{1}\end{array}$ \\
\hline Bovine (pg) & 25 & 19 & 47 \\
Buffalo (pg) & 19 & 13.3 & 36.8 \\
Sheep (pg) & 2.5 & 1.9 & 3.7 \\
Goat (fg) & 350 & 250 & 600 \\
\hline
\end{tabular}

${ }^{1}$ Confidence limit. The LOD was estimated by probit analysis using 24 replicates for each dilution. 
Table 3. Real-time PCR assay: repeatability ${ }^{1}$

\begin{tabular}{lcccccccc}
\hline & \multicolumn{2}{c}{ Mean $\mathrm{C}_{\mathrm{t}}(\mu)$} & & \multicolumn{2}{c}{$\mathrm{SD} \mathrm{C}_{\mathrm{t}}(\sigma)$} & & \multicolumn{2}{c}{$\mathrm{CV}(\%)$} \\
\cline { 2 - 3 } \cline { 7 - 8 } \cline { 7 - 8 } Milk sample & $100 \%$ & $1 \%$ & & $100 \%$ & $1 \%$ & & $100 \%$ & $1 \%$ \\
\hline Bovine & 23.7 & 30.1 & & 0.6 & 0.5 & & 2.5 & 1.7 \\
Buffalo & 22.9 & 29.5 & & 0.2 & 0.7 & & 0.9 & 2.4 \\
Sheep & 23.2 & 29.5 & & 0.2 & 0.4 & & 0.9 & 1.3 \\
Goat & 23.7 & 30.0 & & 0.4 & 0.5 & & 1.7 & 1.7 \\
\hline
\end{tabular}

${ }^{1}$ Repeatability was performed by analyzing 30 replicates in 3 different runs for both $100 \%$ and $1 \%$ in each species-specific assay. The CV was calculated by the formula $(\mathrm{CV}=\mu / \sigma) . \mathrm{C}_{\mathrm{t}}=$ cycle threshold.

sample ID 16 and 17 were prepared from both buffalo and bovine milks fraudulently. Results of sample ID $16(\mathrm{PDO})$ are also reported in Figures 1 and 2, representing IEF and real-time PCR outcomes, respectively. Negative results showed correct $\mathrm{C}_{t}$ values for the IAC in every case, demonstrating that no inhibition was observed.

All samples were analyzed by the IEF reference method and the real-time PCR results were confirmed. Detailed information is reported in Table 4. Moreover, all 3 soy milk samples showed negative results, indicating no cross-reactivity over the 4 assays.

\section{DISCUSSION}

This study described 4 real-time PCR assays based on the amplification of a short sequence of $12 S r R N A$ or cytB mitochondrial DNA. The selected DNA target was mtDNA because each cell contains hundreds of copies, allowing amplification even if cells are present in very low numbers. Moreover, the use of short

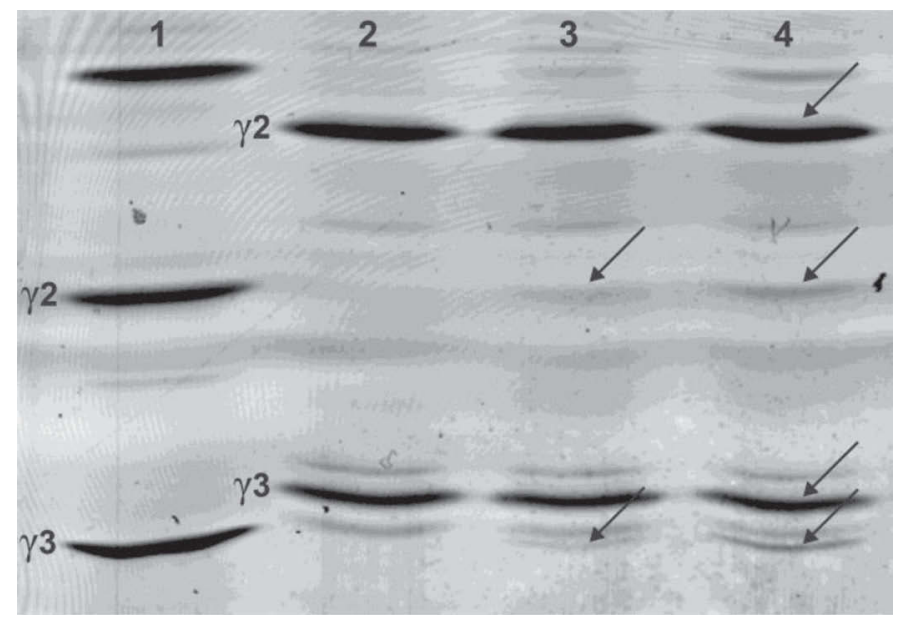

Figure 1. Isoelectric focusing gel of $\gamma$-caseins of sample identification (ID) 16 and bovine/buffalo reference materials. Lane $1=$ reference bovine $100 \%$; lane $2=$ reference buffalo $100 \%$; lane $3=$ reference buffalo $99 \%$, bovine $1 \%$ (arrows shown the $\gamma 2$ and $\gamma 3$ bovine caseins); lane $4=$ sample ID 16. Arrows show both buffalo and bovine $\gamma 2$ and $\gamma 3$-casein bands of a typical mislabeled sample. amplicons enhances the possibility of amplification in dairy products that have undergone intense treatments such as pasteurization, UHT treatment, rennet or acid coagulation, drying, fermentation, ripening, smoking, high pressure treatment, $\mathrm{pH}$ modification, and irradiation. The IAC were also developed for each assay to detect possible false-negative results caused by inhibitory molecules such as spices or other metabolites produced during lactic fermentation.

During the last decade, the PCR-RFLP technique has been widely used for species identification in meat and dairy products (Branciari et al., 2000; Pfeiffer et al., 2004; El Rady and Sayed, 2006; Fajardo et al., 2006); however, if dairy products are prepared by mixing milk from 2 or more species, the interpretation of PCR-RFLP is almost impossible because of the overlap of restriction patterns (Bottero et al., 2003; Dalmasso et al., 2012). Recently, sensory analysis combined with PCR (Golinelli et al., 2014), allelic discrimination (Dalmasso et al., 2011, 2012), high-resolution melting analysis (Sakaridis et al., 2013), and analysis of short species-specific mitochondrial DNA targets (Cottenet et al., 2011; Gonçalves et al., 2012) have been proposed as new and interesting methods that may be used in species identification of dairy products, but none of them used a cut-off of $1 \%$ that unambiguously differentiates between unintentional and fraudulent contamination with cow milk, as reported in the Commission Regulation (EC) No. 273 of 5 March 2008 (European Commission, 2008). Similar considerations were reported in a recent review on animal species identification in food products (Bottero and Dalmasso, 2011).

The analysis conducted on milk mixtures at the $1 \%$ level showed $C_{t}$ values within the range of linearity $\left(R^{2}\right.$ $\geq 0.99$ ) of the standard curve for every species tested. Moreover, the analytical sensitivity calculated for each specific assay was $\leq 25 \mathrm{pg}$, corresponding to $0.5 \%$ of the amount of DNA loaded (5 ng) in the reaction mix.

An important criterion to assess the suitability of a given detection method is the evaluation of the efficiency. If the efficiency decreases, the quantity of PCR products does not double at each cycle and the amplification plot will be delayed. The Applied Biosystems 
application note recommends efficiency values between 90 and $110 \%$ for high performance of real-time PCR methods. In the present study, the calculated efficiency values were $96,97,99$, and $99 \%$ for B. bubalis, B. taurus, $C$. hircus, and $O$. aries, respectively.

A precautionary approach in the present study caused us to consider only semiquantitative purposes because accurate quantitative determination of different milk percentages in mixed-milk cheeses is still problematic. Indeed, because DNA is derived only from somatic cells that can vary from physiological to nonphysiological (e.g., mastitis) levels and because several factors in cheese technology may influence the final DNA con- centration, DNA-based methods can only provide approximate values (Mayer et al., 2012).

Besides mass spectrometry techniques (Linder et al., 2010; Calvano et al., 2013), different authors have proposed molecular assays to detect bovine milk in dairy products (López-Calleja et al., 2007b,c; Mafra et al., 2007; Zhang et al., 2007; Cottenet et al., 2011; Dalmasso et al., 2012; Rentsch et al., 2013; Sakaridis et al., 2013), but only Gonçalves et al. (2012) and Agrimonti et al. (2015) have developed a method for the simultaneous identification of milk from cow, sheep, goat, and water buffalo as described in the present work. The analysis of short species-specific mitochondrial DNA targets

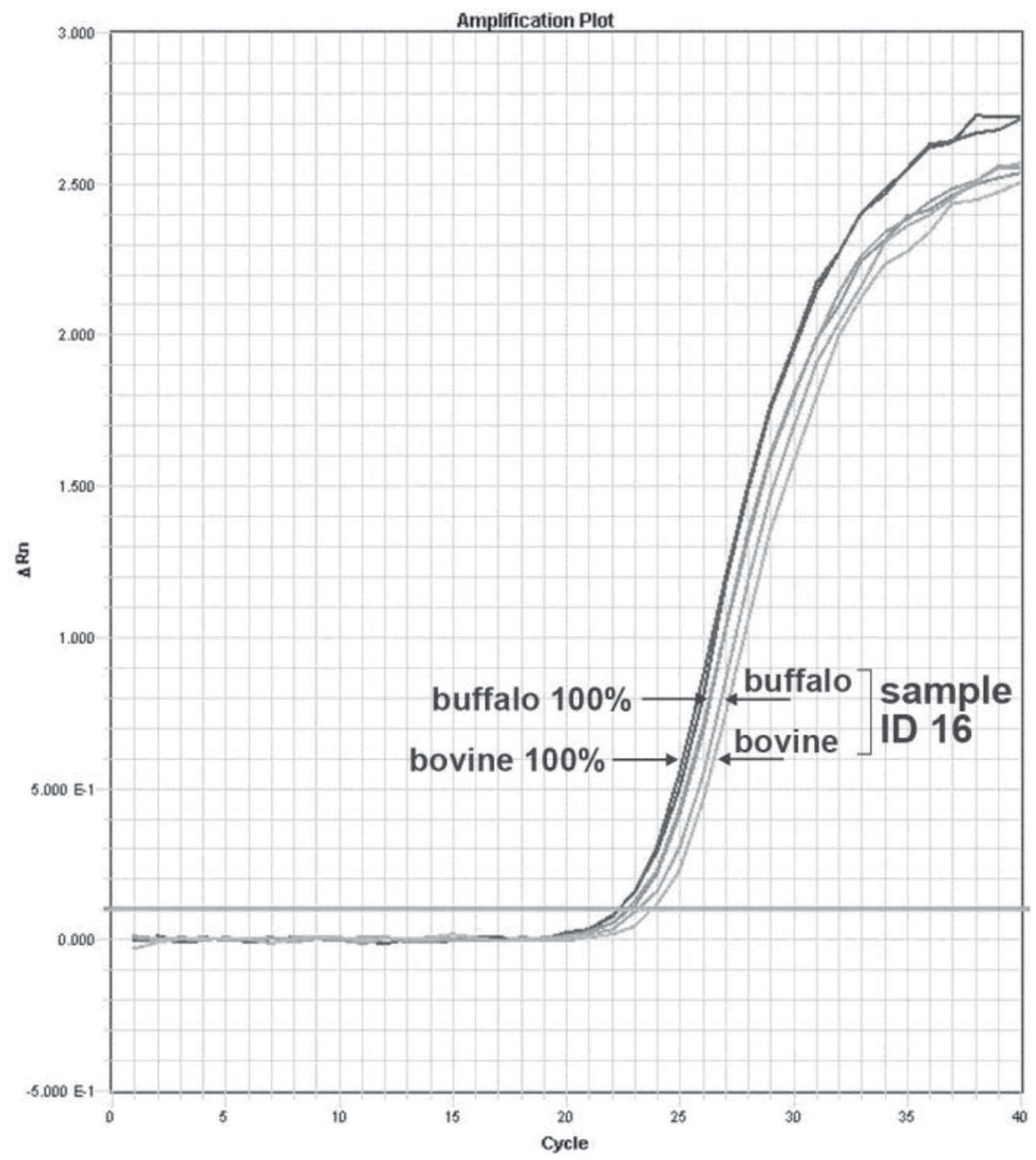

Figure 2. Amplification plot of the real-time PCR. Sample identification (ID) 16 shows amplification for both bovine and buffalo assays. 
Table 4. Real-time PCR and isoelectric focusing (IEF) results of commercial samples ${ }^{1}$

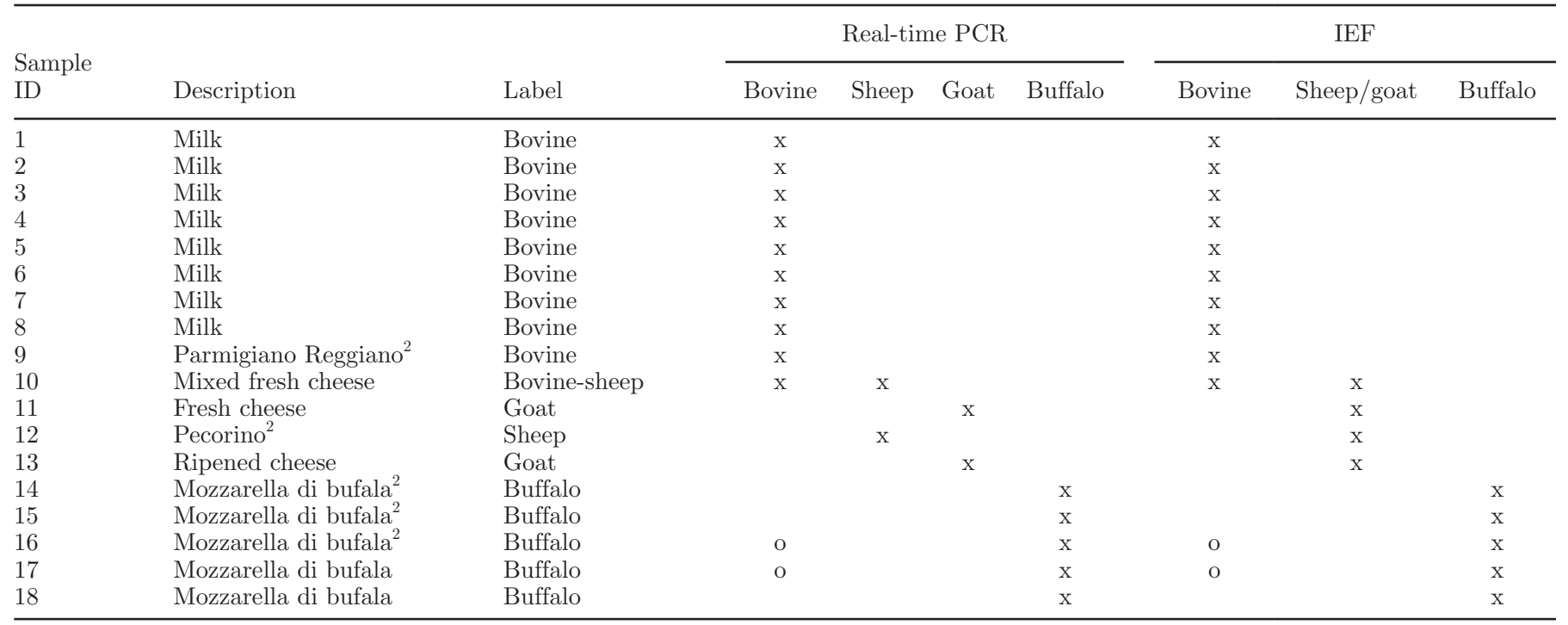

${ }^{1} \mathrm{x}=$ species reported in label detected by both methods; o $=$ species not declared in label detected by both methods.

${ }^{2}$ Samples identified as protected designation of origin.

proposed by Gonçalves et al. (2012) represented a reliable alternative method to real-time PCR even though it was more expensive and time consuming. In contrast, in Agrimonti et al. (2015), the quadriplex SYBR GreenER PCR developed failed to detect goat and sheep milk in $20 \%$ of the cheese samples analyzed. Moreover, the authors also reported the low efficiency in quantification $\left(\mathrm{R}^{2}<0.7\right)$ for cheeses, for which TaqMan probes gave better results. Only a few validated real-time PCR methods have been published (Lopparelli et al., 2007; Rentsch et al., 2013); however, the present study is the first validation report of a real-time PCR supported by the analysis of commercial samples confirmed by IEF, the official European Union reference method.

This study demonstrated several advantages of the use of real-time PCR analysis: (a) it is a time-saving procedure, (b) it can discriminate between goat and sheep milks, (c) it is a semiquantitative method, (d) it is applicable in soy milk products, and (e) it generally has a high throughput. The advantages and the good diagnostic performances of the real-time PCR assays developed in the present study, in terms of sensitivity, specificity, and repeatability, suggest that this method may be useful and reliable for routine species identification in milk and dairy products.

\section{ACKNOWLEDGMENTS}

Funding was provided by the Italian Ministry of Health. Mention of trade names or commercial products in this article is solely for the purpose of providing specific information and does not imply recommenda- tion or endorsement by the Istituto Zooprofilattico Sperimentale dell'Abruzzo e del Molise "G. Caporale."

\section{REFERENCES}

Addeo, F., L. Moio, L. Chianese, C. Stingo, P. Resmini, I. Berner, I. Karause, A. Di Luccia, and A. Bocca. 1990. Use of plasmin to increase the sensitivity of the detection of bovine milk in ovine cheese by gel isoelectric focusing of $\gamma 2$-caseins. Milchwissenschaft 45:708.

Agrimonti, C., A. Pirondini, M. Marmiroli, and N. Marmiroli. 2015. A quadruplex PCR (qxPCR) assay for adulteration in dairy products. Food Chem. 187:58-64.

Bottero, M. T., T. Civera, D. Numera, S. Rosati, P. Sacchi, and R. M. Turi. 2003. A multiplex polymerase chain reaction for the identification of cows', goats' and sheep's milk in dairy products. Int. Dairy J. 13:277-282.

Bottero, M. T., and A. Dalmasso. 2011. Animal species identification in food products: Evolution of biomolecular methods. Vet. J. 190:34-38.

Branciari, R., I. J. Nijman, M. E. Plas, E. Di Antonio, and J. A. Lenstra. 2000. Species origin of milk in Italian Mozzarella and Greek Feta cheese. J. Food Prot. 63:408-411.

Calvano, C. D., C. De Ceglie, A. Aresta, L. A. Facchini, and C. G. Zambonin. 2013. MALDI-TOF mass spectrometric determination of intact phospholipids as markers of illegal bovine milk adulteration of high-quality milk. Anal. Bioanal. Chem. 405:1641-1649.

Cammà, C., M. Di Domenico, and F. Monaco. 2012. Development and validation of fast real time PCR assays for species identification in raw and cooked meat mixtures. Food Contr. 23:400-404.

Cerquaglia, O., and P. Avellini. 2004. A rapid $\gamma$-casein isoelectrofocusing method for detecting and quantifying bovine milk used in cheese making: Application to sheep cheese. Ital. J. Food Sci. 16:447-455.

Cottenet, G., C. Blancpain, and P. A. Golay. 2011. Simultaneous detection of cow and buffalo species in milk from China, India, and Pakistan using multiplex real-time PCR. J. Dairy Sci. 94:37873793.

Cozzolino, R., S. Passalacqua, S. Salemi, and D. Garozzo. 2002. Identification of adulteration in water buffalo mozzarella and in ewe cheese by using whey proteins as biomarkers and matrix-assisted 
laser desorption/ionization mass spectrometry. J. Mass Spectrom. 37:985-991.

Dalmasso, A., T. Civera, F. La Neve, and M. T. Bottero. 2011. Simultaneous detection of cow and buffalo milk in mozzarella cheese by real time PCR assay. Food Chem. 124:362-366.

Dalmasso, A., P. Sacchi, and M. T. Bottero. 2012. Development of a real-time PCR assay for the detection of cow and donkey milk. Eur. Food Res. Technol. 235:47-52.

European Commission. 2002. EC Regulation No 178/2002 of the European Parliament and of the Council of 28 January 2002 laying down the general principles and requirements of food law, establishing the European Food Safety Authority and laying down procedures in matters of food safety.

European Commission. 2008. Commission Regulation (EC) No 273/2008 of 5 March 2008 laying down detailed rules for the application of Council Regulation (EC) No. 1255/1999 as regards methods for the analysis and quality evaluation of milk and milk products. Official Journal of the European Union, 29.3.2008, L $88 / 1$.

European Commission. 2012. Regulation (EU) No 1151/2012 of the European Parliament and of the Council of 21 November 2012 on quality schemes for agricultural products and foodstuffs.

El Rady, A., and M. Sayed. 2006. Identification of milk source by polymerase chain reaction-restriction fragment length polymorphism analysis. J. Rapid Meth. Auto. Microbiol. 14:146-155.

Fajardo, V., I. González, I. López-Calleja, I. Martin, P. E. Hernández, T. García, and R. Martín. 2006. PCR-RFLP authentication of meats from red deer (Cervus elaphus), fallow deer (Dama dama), roe deer (Capreolus capreolus), cattle (Bos taurus), sheep (Ovis aries), and goat (Capra hircus). J. Agric. Food Chem. 54:1144-1150.

Finney, D. J. 1971. Probit Analysis. 3rd ed. Cambridge University Press, Cambridge, UK.

Golinelli, L. P., A. C. Carvalho, R. S. Casaes, C. S. C. Lopes, R. Deliza, V. M. F. Paschoalin, and J. T. Silva. 2014. Sensory analysis and species-specific PCR detect bovine milk adulteration of frescal (fresh) goat cheese. J. Dairy Sci. 97:6693-6699.

Gonçalves, J., F. Pereira, A. Amorim, and B. van Asch. 2012. New method for the simultaneous identification of cow, sheep, goat, and water buffalo in dairy products by analysis of short, species-specific mitochondrial DNA targets. J. Agric. Food Chem. 60:1048010485 .

Iwobi, A., D. Sebah, I. Kraemer, C. Losher, G. Fischer, U. Busch, and I. Huber. 2015. A multiplex real-time PCR method for the quantification of beef and pork fractions in minced meat. Food Chem. 169:305-313.

Linder, W., C. Czerwenka, and L. Müller. 2010. Detection of the adulteration of water buffalo milk and mozzarella with cow's milk by liquid chromatography-mass spectrometry analysis of B-lactoglobulin variants. Food Chem. 122:901-908.

López-Calleja, I., I. González, V. Fajardo, P. E. Hernández, T. García, and R. Martín. 2007a. Quantitative detection of goats' milk in sheep's milk by real time PCR. Food Contr. 18:1466-1473.
López-Calleja, I., I. Gonzàlez Alonso, V. Fajardo, M. A. Rodrìguez, P. E. Hernàndez, T. García, and R. Martín. 2007b. Real time TaqMan PCR for quantitative detection of cows' milk in ewes' milk mixtures. Int. Dairy J. 17:729-736.

López-Calleja, I., I. Gonzàlez Alonso, V. Fajardo, M. A. Rodrìguez, P. E. Hernàndez, T. García, and R. Martín. 2007c. Application of an indirect ELISA and a PCR technique for detection of cows' milk in sheep's and goats' milk cheeses. Int. Dairy J. 17:87-93.

Lopparelli, R. M., B. Cardazzo, S. Balzan, V. Giaccone, and E. Novelli. 2007. Real time TaqMan polymerase chain reaction detection and quantification of cow DNA in pure water buffalo Mozzarella cheese: Method validation and its application on commercial samples. J. Agric. Food Chem. 55:3429-3434.

Mafra, I., A. Roxo, I. M. P. L. V. O. Ferreira, and M. B. P. P. Oliveira. 2007. A duplex polymerase chain reaction for the quantitative detection of cows' milk in goats' milk cheese. Int. Dairy J. $17: 1132-1138$

Mayer, H. K. 2005. Milk species identification in cheese varieties using electrophoretic, chromatographic and PCR techniques. Int. Dairy J. 15:595-604.

Mayer, H. K., J. Bürger, and N. Kaar. 2012. Quantification of cow's milk percentage in dairy products-A myth? Anal. Bioanal. Chem. 403:3031-3040.

Mayer, H. K., D. Heidler, and C. Rockenbauer. 1997. Determination of the percentages of cows', ewes' and goats' milk in cheese by isoelectric focusing and cation-exchange HPLC of $\gamma$ - and para- $\kappa$-caseins. Int. Dairy J. 7:619-628.

Pfeiffer, I., J. Burger, and B. Brenig. 2004. Diagnostic polymorphisms in the mitochondrial cytochrome $\mathrm{b}$ gene allow discrimination between cattle, sheep, goat, roe buck and deer by PCR-RFLP. BMC Genet. 5:30.

Rentsch, J., S. Weibel, J. Ruf, A. Eugster, K. Beck, and R. Koppel. 2013. Interlaboratory validation of two multiplex quantitative realtime PCR methods to determine species DNA of cow, sheep and goat as a measure of milk proportions in cheese. Eur. Food Res. Technol. 236:217-227.

Sakaridis, I., I. Ganopoulos, A. Argiriou, and A. Tsaftaris. 2013. High resolution melting analysis for quantitative detection of bovine milk in pure water buffalo mozzarella and other buffalo dairy products. Int. Dairy J. 28:32-35.

Vaerman, J. L., P. Saussoy, and I. Ingargiola. 2004. Evaluation of real-time PCR data. J. Biol. Regul. Homeost. Agents 18:212-214.

van Hengel, A. J. 2007. Food allergen detection methods and challenge to protect food-allergic consumers. Anal. Bioanal. Chem. 389:111-118.

Zhang, C., M. R. Fowler, N. W. Scott, G. Lawson, and A. Slater. 2007. A TaqMan real-time PCR system for the identification and quantification of bovine DNA in meats, milks and cheeses. Food Contr. 18:1149-1158. 